\title{
Análise de ofertas de emprego para bibliotecários de referência
}

\author{
Daniela Capri \\ Acadêmica de Biblioteconomia \\ Universidade Federal de Santa Catarina - Brasil \\ Renata Duarte de Borja \\ Acadêmica de Biblioteconomia \\ Universidade Federal de Santa Catarina - Brasil \\ Ana Cláudia Zandavalle \\ Acadêmica de Biblioteconomia \\ Universidade Federal de Santa Catarina - Brasil \\ Miriam Vieira da Cunha \\ Professora do Departamento de Ciência da Informação \\ Universidade Federal de Santa Catarina - Brasil
}

\section{ARTIGO / ARTICLE}

\section{Resumo}

O papel do bibliotecário de referência é essencial para o atendimento do usuário. Esta pesquisa analisou e comparou as ofertas para bibliotecários de referência nos sites Indeed e Jobs. Utilizou a técnica de análise de conteúdo de Bardin. Os resultados revelaram que o mercado de trabalho procura profissionais pró-ativos, comunicativos e experientes, com formação em Biblioteconomia ou Ciência da Informação.

Palavras-chave

Bibliotecários de referência ; Mercado de trabalho ; Ofertas de emprego ; Análise de conteúdo

\section{Analysis of job offers for reference librarians}

\section{Abstract}

The role of the reference librarian is essential for assistence of users. This paper analysed and compared job offers for reference librarians in the websites Indeed and Jobs. It used Bardin's content analysis technique. The results revealed that the job market looks for pro-active and expert professionals with Library or Information Science education.

Keywords

Reference librarians ; Labour market ; Job offers ; Content analysis 


\section{Introdução}

O serviço de referência pode ser entendido como a assistência individual a usuários que buscam informação. A finalidade deste serviço é permitir que as informações fluam eficientemente entre as fontes de informação e quem necessita delas (GROGAN, 2001). Segundo este autor, existem dois tipos de ajuda que o bibliotecário pode exercer na função de referência: a função informacional e a função instrucional. A referência, como função instrucional, apresenta-se como um serviço de educação de usuários que pode ser realizada em grupos. Já no sentido informacional, responde às questões feitas pelos usuários.

Embora exerça uma função específica, o bibliotecário de referência deve conhecer seu ambiente de trabalho - a biblioteca. Nesse ambiente, esse profissional é considerado um mediador entre o leitor e os documentos. Entre as suas características estão a boa comunicação, a capacidade de instrução e a experiência com tecnologias.

O objetivo deste artigo é analisar e comparar as ofertas de emprego para bibliotecários de referência nos sites Indeed e Jobs.

\section{A função de referência}

A função de referência foi reconhecida em 1884, por Melvil Dewey, influenciando a vulgarização do hábito de leitura nos EUA. Com este reconhecimento, Dewey acreditava no poder dos bibliotecários para desenvolver novas tarefas e serviços (OCHÔA, 2005 apud SILVA, 2006, p. 47). O trabalho de referência é uma atividade essencialmente humana, sendo considerada o "cartão de visitas" da biblioteca. Atende a uma das necessidades mais profundamente arraigadas nas pessoas, o anseio de conhecer e compreender. A partir dessa necessidade, as atividades do bibliotecário de referência giram em torno do usuário, desencadeando o serviço a partir da formulação de uma questão.

Segundo Merlo Vega (2000):

Se uma das funções da biblioteca é informar, o objetivo principal do serviço de referência será conseguir que todas as informações solicitadas sejam satisfeitas. Por esta razão, a biblioteca deve ter uma seção específica, com pessoal especializado na busca de informação e com uma coleção de consulta adequada. Deve também desenvolver iniciativas e procedimentos que julgar necessários para dar aos usuários acesso à informação (MERLO VEGA, 2000, p. 94-95, Tradução Nossa) $)^{1}$.

Sobre o espaço físico do serviço de referência, Merlo Vega (2000) afirma que deve estar bem sinalizado e facilmente localizável, de preferência, próximo à entrada principal da biblioteca. Os modelos norte-americanos e europeus de organização física da biblioteca adotam a idéia de "balcão de referência", permitindo, dessa forma, um acesso fácil. Já no modelo sul americano, a departamentalização das organizações, faz com que as bibliotecas sejam frequentemente divididas em setores. (CHIAVENATO, 2000). Para este autor, os serviços de referência podem ser classificados em serviços de informação, de formação e de orientação, conforme tabela a seguir:

Grogan (2001, p. 8) afirma que "o serviço de referência [...] é mais do que um expediente para a comodidade do usuário." Nesses sentido, esse serviço tem como premissa responder a questões de qualquer natureza. A tríade informação, formação e orientação está diretamente ligada à tipologia das unidades de informação. A biblioteca especializada demanda do bibliotecário informações e respostas pontuais.. Já as bibliotecas públicas e aquelas ligadas a instituições de ensino, devem preoucupar-se com a formação do usuário.

Carvalho e Lucas (2005) afirmam que os serviços de referência digital representam um progresso para a área e uma vantagem competitiva a ser considerada pelas unidades de informação. Neste sentido, para Sayão (2009) os serviços digitais não são apenas recriações de ideias estabelecidas, mas ideias aprimoradas e adaptadas a novos ambientes, através das tecnologias disponíveis.

\footnotetext{
${ }^{1}$ Si una de la funciones de la biblioteca es informar, el principal objetivo del servicio de referencia será conseguir que todas las informaciones requeridas sean satisfechas. Por este motivo, la biblioteca deberá contar con una sección específica, con personal especializado en la búsqueda de información y con uma colección de consulta útil. Además, deberá desarrollar las iniciativas y procedimientos que considere necesarios para facilitar al usuario el acceso a la información.
} 


\begin{tabular}{|c|c|c|}
\hline Tipos de Serviços & Descrição & Exemplos \\
\hline Informação & $\begin{array}{l}\text { Responder a perguntas dos } \\
\text { usuários }\end{array}$ & $\begin{array}{l}\text { Perguntas rápidas, pesquisas } \\
\text { bibliográficas, obtenção de } \\
\text { documentos. }\end{array}$ \\
\hline Formação & $\begin{array}{l}\text { Educar o usuário na } \\
\text { utilização da biblioteca e da } \\
\text { coleção de referência }\end{array}$ & Formação de usuários. \\
\hline Orientação & $\begin{array}{l}\text { Aconselhar o usuário na } \\
\text { escolha de uma obra ou fonte } \\
\text { de informação }\end{array}$ & $\begin{array}{l}\text { Atividades desenvolvidas pela } \\
\text { biblioteca para recomendar ou } \\
\text { divulgar } \\
\text { documentos. }\end{array}$ \\
\hline
\end{tabular}

Tabela 1 - Tipologia dos serviços de informação.

Fonte: BOPP 1995 apud MERLO VEGA, 2000, p. 97 (adaptação).

\section{O Bibliotecário de referência}

A idéia do bibliotecário de referência como mediador da informação tem sido discutida com ênfase desde o surgimento das TICs. A desintermediação da informação é uma discussão recente, mas não menos importante, uma vez que lida diretamente com a questão do posicionamento profissional frente às novas tecnologias.

Lopes e Silva (2011) acreditam que as novas tecnologias abrem possibilidades para novas formas de mediação, como a orientação no uso das tecnologias da informação.

De acordo com Merlo Veja (2003), os bibliotecários de referência têm um novo perfil, que os obriga a ser especialistas em recursos de informação e recuperação de dados. Este autor acredita que este profissional deve reunir uma série de características tais como:

- ter formação na área de Biblioteconomia;

- conhercer fontes de referência;

- ter capacidade de análise e síntese, para delimitar as consultas dos usuários e para que as respostas se ajustem às perguntas;

- $\quad$ ser especialista em sistemas de busca e acesso à informação;

- familiarizar-se com as tecnologias e com as fontes de referência eletrônica;

- reconhecer as necessidades informacionais dos usuários para elaboração de serviços e produtos tais como bibliografias, guias, ou similares, com temas e informações de interesse.

- possuir características pessoais como: proatividade, objetividade, nível cultural avançado e bom relacionamento interpessoal (Merlo Veja, 2000).

O quadro abaixo nos mostra a evolução das características dos profissionais de referência de 1984 até o ano 2000. Pode-se verificar que, com o passar do tempo, ampliou-se a necessidade de especialização em tecnologias e gestão de serviços: 


\begin{tabular}{|c|c|}
\hline 1984 & 1985 \\
\hline $\begin{array}{l}\text { - Comunicação com os outros; } \\
\text { - Capacidade de analisar necessidades de } \\
\text { informação; } \\
\text { - Capacidade de encontrar informação; } \\
\text { - Capacidade de ensinar utilizadores; } \\
\text { - Supervisão de equipes; } \\
\text { - Conhecimento dos principais materiais de } \\
\text { referência; } \\
\text { - Capacidade de relacionamento interpessoal; } \\
\text { - Conhecimento de bibliografias gerais. }\end{array}$ & $\begin{array}{l}\text { - Habilidade para conduzir uma entrevista de } \\
\text { referência; } \\
\text { - Conhecimento dos materiais de referência; } \\
\text { - Capacidade de conduzir uma entrevista em } \\
\text { base de dados; } \\
\text { - Capacidade de encontrar materiais de } \\
\text { informação; } \\
\text { - Orientação para outras fontes de informação; } \\
\text { - Demonstrar interação c/ políticas de } \\
\text { biblioteca. }\end{array}$ \\
\hline 1989 & 1990 \\
\hline $\begin{array}{l}\text { - Conhecimento de instrumentos bibliográficos; } \\
\text { - Relações interpessoais; } \\
\text { - Seleção e avaliação de fontes de informação; } \\
\text { - Condução de entrevistas de referência; } \\
\text { - Orientação do utilizador; }\end{array}$ & $\begin{array}{l}\text { - Técnicas de entrevista de referência; } \\
\text { - Uso de tecnologia; } \\
\text { - Gestão do setor de referência; } \\
\text { - Interesse e habilidade para trabalhar com } \\
\text { pessoas; } \\
\text { - Conhecimento de fontes de referência; } \\
\text { - Competência para ouvir; } \\
\text { - Competência para ensinar; } \\
\text { - Dominar técnicas documentais inovadoras; } \\
\text { - Dominar instrumentos de estratégia de } \\
\text { pesquisa; }\end{array}$ \\
\hline 1991 & 1998 \\
\hline $\begin{array}{l}\text { - Conhecimento de técnicas e fontes de } \\
\text { informação informatizadas e tradicionais; } \\
\text { - Capacidade de encontrar informação; } \\
\text { - Conhecimentos tecnológicos vastos; } \\
\text { - Capacidade de ensinar; } \\
\text { - Conhecimentos de gestão; } \\
\text { - Análise de necessidades de informação; }\end{array}$ & $\begin{array}{l}\text { - Análise de desempenho e técnicas de gestão } \\
\text { da qualidade; } \\
\text { - Conhecimentos tecnológicos vastos; } \\
\text { - Capacidade de ensinar; } \\
\text { - Capacidade de motivar; } \\
\text { - Técnicas de pesquisa; } \\
\text { - Gestão de equipes. }\end{array}$ \\
\hline \multicolumn{2}{|c|}{2000 - Competências do MERCOSUL } \\
\hline \multicolumn{2}{|c|}{$\begin{array}{l}\text { - Capacitar e orientar os usuários para um melhor uso das unidades de informação e seus } \\
\text { recursos. } \\
\text { - Elaborar produtos de informação (bibliografias, catálogos, guias, índices, DSI, etc); } \\
\text { - Planificar e executar estudos de usuários/clientes de informação e formação de usuários/clientes } \\
\text { de informação; } \\
\text { - Buscar, registrar, armazenar, recuperar e disseminar a informação gravada em qualquer meio } \\
\text { para os usuários de unidades, serviços e sistemas de informação; } \\
\text { - Utilizar e disseminar fontes, produtos e recursos de informação em diferentes suportes; } \\
\text { - Buscar, registrar, avaliar e disseminar a informação com fins acadêmicos e profissionais; } \\
\text { - Planificar, criar e utilizar redes globais de informação; } \\
\text { - Identificar novas demandas sociais de informação; }\end{array}$} \\
\hline
\end{tabular}

Tabela 2 - Evolução das competências profissionais.

Fonte: Quadro 3 - Competências do bibliotecário de referência.

Fonte: Silva (2006)

Observando as competências apresentadas a partir de 1990, quando a utilização das tecnologias se torna uma constante, fica evidente a necessidade do bibliotecário atualizar-se constantemente. Grogan (2001) afirma que para realizar um serviço de referência de qualidade é necessário que o bibliotecário possua atributos profissionais tais como competência profissional, intimidade com as fontes, domínio de técnicas de busca, vasta cultura geral, experiência em lidar com o usuário e talento para se comunicar. Entre os atributos pessoais estão: simpatia, criatividade, confiança, cortesia, tato, interesse pelas pessoas, imaginação, adaptabilidade, iniciativa, diligência, paciência, entusiasmo, persistência, humildade e devoção ao serviço. 


\section{Metodologia}

Esta pesquisa é documental (GIL, 2002), qualitativa e quantitativa. Para a análise dos dados foi utilizada a técnica de Análise de Conteúdo, de Bardin (2010). A representação do conteúdo de acordo com a autora pode propor "inferências e adiantar interpretações a propósito dos objetivos previstos - ou que digam respeito a outras descobertas inesperadas" (BARDIN, 2010, p. 127). Foram escolhidas para a análise duas bases de dados internacionais de ofertas de emprego - Indeed - Norte Americana, e Jobs - Inglesa.

A busca nos sites Indeed <http://www.indeed.com/> e Jobs <http://www.jobs.ac.uk/> foi realizada no período de 4 de abril a 28 de maio de 2011. A expressão de busca utilizada em ambos foi "reference librarian" (bibliotecário de referência). Quando a pesquisa retornava poucos resultados, utilizamos a palavra "librarian" (bibliotecário). O corpus da pesquisa cobre um total de 40 anúncios para bibliotecários e bibliotecários de referência, sendo 10 do site Jobs e 30 do site Indeed.

\section{Análise e discussão dos resultados}

No site inglê Jobs, a busca por "reference librarian" recuperou apenas 3 resultados. Posteriormente foi feita uma busca pela palavra "librarian" e então foram recuperados 10 resultados referentes a vagas para bibliotecários disponíveis na Inglaterra e em outros países. No site Indeed foram recuperados 367 itens, contabilizando vagas para os Estados Unidos da América. Como o tempo disponível não permitia a análise de todas as ofertas, decidiu-se fazer a análise das 30 mais recentes.

Quando da tabulação e análise dos dados, algumas variáveis foram identificadas tais como: a) País da oferta; b) Tipo de Instituição Empregadora; c) Nome do Cargo; d) Requisitos de Formação e) Experiência; f) Características Pessoais e g) Atributos Desejáveis. O gráfico a seguir apresenta os países de origem das ofertas analisadas:

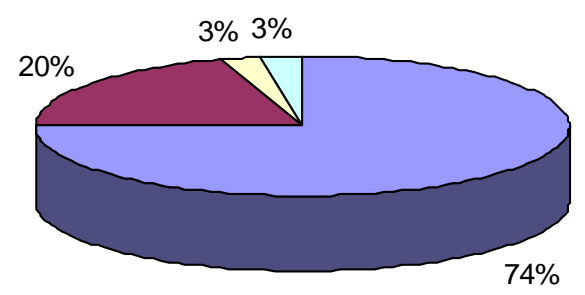

$\square$ Estados Unidos $\square$ Inglaterra $\square$ Hong Kong $\square$ Zimbábue

Gráfico 1 - Países das ofertas de empregos recuperadas.

Todas as ofertas do site Indeed, são provenientes dos Estados Unidos da América, contabilizando 30 vagas. Das dez vagas recuperadas no site Jobs, 8 eram provenientes da Inglaterra, uma do Zimbabue e outra de Hong Kong, contabilizando 10 vagas. Na Tabela 1, a seguir, é possível verificar a tipologia das instituições encontradas nas ofertas de emprego analisadas: 


\begin{tabular}{|l|c|c|c|c|}
\hline \multicolumn{1}{|c|}{ Instituição } & Indeed & Jobs & Total & $\%$ \\
\hline Universidade & 27 & 9 & 36 & 90 \\
\hline Empresa Privada & 1 & 1 & 2 & 5 \\
\hline Exército & 1 & - & 1 & 2,5 \\
\hline Biblioteca Pública & 1 & - & 1 & 2,5 \\
\hline Total & 30 & 10 & 40 & 100 \\
\hline
\end{tabular}

Tabela 3 - Tipologia das Instituições Empregadoras.

Como se pode constatar, as universidades representam $90 \%$ do total de anúncios. Entre as empresas privadas que solicitam bibliotecários estão a Zimmerman Associates Inc., uma empresa de inteligência competitiva, no site Indeed e a Natural History Book Service (NHBS), uma livraria online, recuperada, no site Jobs. Foi encontrado também um anúncio para a Biblioteca Estadual do Estado do Kansas e uma vaga para a biblioteca da área de Saúde do Exército Norte Americano.

Observamos também que o site Jobs apresenta duas vagas de estágio (uma para mestrandos e outra para pósdoutorandos) para a Universidade de Cambridge. Estas vagas têm características específicas, uma vez que o comprometimento do candidato é temporário. Na tabela 2, a seguir, é possível verificar a nomenclatura dos cargos das ofertas analisadas.

\begin{tabular}{|l|c|c|c|c|}
\hline \multicolumn{1}{|c|}{ Cargo } & Indeed & Jobs & Total & $\%$ \\
\hline Bibliotecário de Referência & 22 & 1 & 23 & $57,5 \%$ \\
\hline Bibliotecário & 7 & - & 7 & $17,5 \%$ \\
\hline Bibliotecário Universitário & - & 6 & 6 & $15 \%$ \\
\hline Bibliotecário de TI & 1 & - & 1 & $2,5 \%$ \\
\hline Outros & - & 3 & 3 & $7,5 \%$ \\
\hline Total & 30 & 10 & 40 & $100 \%$ \\
\hline
\end{tabular}

Tabela 4 - Nomenclatura dos Cargos.

É possível observar que a maior parte dos anúncios recuperados são para bibliotecários de referência (57,5\%), com vagas específicas para "bibliotecários de referência e instrução" e para "bibliotecário de referência temporário". Vagas para "Bibliotecário," por vezes, apresentam também especificidades, como conhecimentos em farmácia, catalogação, negócios e experiências na web, informações governamentais e coordenação em desenvolvimento de coleções.

É curioso notar que, apesar de cerca de 90\% das instituições empregadoras serem universidades, apenas $15 \%$ utilizam o termo "bibliotecário universitário". Também existem vagas para bibliotecários de TI. Na menção "outros" encontram-se vagas de Bolsa de Pesquisa Munby de Bibliografia e para estagiário de Pós-Graduação em Biblioteconomia, ambas para a Universidade de Cambridge. Outra vaga classificada como "outros" foi a de Editor de Catalogação da Natural History Book Service. Para este anúncio, o candidato pode ser bibliotecário, biólogo ou de outra área correlata.

As tabelas apresentadas a seguir, mostram a formação e a experiência solicitadas. 


\begin{tabular}{|l|c|c|c|}
\hline & Indeed & Jobs & Total \\
\hline $\begin{array}{l}\text { Bacharelado (em qualquer área) e Pós-Graduação em } \\
\text { Biblioteconomia e Ciência da informação acreditada pela ALA } \\
\text { - ou equivalente; experiência comprobatória; }\end{array}$ & 29 & 6 & 35 \\
\hline Nenhum requisito de formação & 1 & 4 & 5 \\
\hline TOTAL & 30 & 10 & 40 \\
\hline
\end{tabular}

Tabela 5 - Requisitos de formação.

De acordo com a Tabela 5, 35 ofertas (o que representa 87,5\% do total) deixam explícita a necessidade de formação em qualquer área e pós-graduação em Biblioteconomia e Ciência da Informação acreditada pela American Library Association (ALA) ou equivalente. A Tabela 6, apresenta a experiência demandada:

\begin{tabular}{|l|c|c|c|}
\hline & Indeed & Jobs & Total \\
\hline Experiência profissional em ambiente de biblioteca; & 12 & 3 & 15 \\
\hline $\begin{array}{l}\text { Experiência com Tecnologias de Informação e Comunicação); } \\
\text { Habilidade em informática; }\end{array}$ & 6 & 9 & 15 \\
\hline $\begin{array}{l}\text { Experiência em Ensino e Instrução; Treinamento; Competência } \\
\text { Informacional; }\end{array}$ & 7 & 5 & 12 \\
\hline Nenhum requisito de experiência & 5 & 3 & 8 \\
\hline TOTAL & 30 & 10 & 40 \\
\hline
\end{tabular}

Tabela 6 - Requisitos de experiência.

A experiência profissional é demandada em 37,5\% das ofertas, sendo, na maioria dos casos, experiência em bibliotecas, TICs e informática. A experiência com instrução de usuários e competência informacional é exigência em $30 \%$ das vagas, demonstrando que a habilidade de lidar com o público deve ir além das consultas individuais.

A Tabela 7, nos mostra os termos mais freqüentes encontrados nas ofertas analisadas referentes às características pessoais dos candidatos. As quatro características mais requisitadas são respectivamente: boa comunicação oral e escrita (14 ofertas); habilidade em gestão (8 ofertas); organização (8 ofertas) comprometimento e flexibilidade (8 ofertaas cada uma, respectivamente). Outras características demandadas são: independência, criatividade, iniciativa, liderança e auto-motivação.

Além destas características, são solicitadas: cidadania ou visto norte americano (2 ofertas); participação, integridade, profissionalismo, interesse em livros impressos antigos e conhecimento de história da bibliografia, alta competência em sistemas automatizados de bibliotecas.

Foram analisadas também as características que os empregadores consideram desejáveis. Entre essas são citadas: experiência profissional, conhecimento de TICs e fontes online e experiência com ensino e instrução. Entre as características profissionais desejáveis encontram-se: ter bom relacionamento interpessoal, capacidade para criação de material informativo e instrucional, comprometimento e boa comunicação. Na Tabela 8 é possível verificar que os atributos desejáveis foram recuperados em maior quantidade no site Indeed: 


\begin{tabular}{|l|c|c|c|}
\hline $\begin{array}{l}\text { Características Pessoais } \\
\text { (respostas múltiplas) }\end{array}$ & Indeed & Jobs & Total \\
\hline Comunicação & 13 & 1 & 14 \\
\hline Habilidade em Gestão & 8 & - & 8 \\
\hline Organização & 7 & 1 & 8 \\
\hline Comprometimento & 5 & 2 & 7 \\
\hline Flexibilidade & 5 & - & 5 \\
\hline Independência & 4 & - & 4 \\
\hline Criatividade & 3 & - & 3 \\
\hline Iniciativa & 3 & - & 3 \\
\hline Liderança & 3 & - & 3 \\
\hline Auto-motivação & 2 & - & 2 \\
\hline Auto-motivação & 2 & - & 2 \\
\hline Auto-motivação & 2 & - & 2 \\
\hline
\end{tabular}

Tabela 7 - Características pessoais.

\begin{tabular}{|l|c|c|}
\hline Atributos Desejáveis (respostas múltiplas) & Indeed & Jobs \\
\hline $\begin{array}{l}\text { Experiência profissional em biblioteca ou com serviço de } \\
\text { referência }\end{array}$ & 14 & - \\
\hline Conhecimento de Fontes Online e experiência com TICs & 11 & - \\
\hline $\begin{array}{l}\text { Experiência em Ensino e Instrução; Treinamento; } \\
\text { Literacia Informacional; }\end{array}$ & 8 & - \\
\hline Bom relacionamento interpessoal & 3 & - \\
\hline Criação de material informativo e instrucional & 3 & - \\
\hline Comprometimento & 3 & - \\
\hline Comunicação & 3 & - \\
\hline
\end{tabular}

Tabela 8 - Atributos desejáveis.

Além destes atributos, foram citados ainda: foco em serviços; iniciativa, organização, solução de problemas; experiência em gestão de projetos; experiência em Desenvolvimento de Coleções; experiência em supervisão; conhecimento de material jurídico; proficiência em gestão financeira e planejamento orçamentário; habilidade de pensar criativamente em serviços de desenvolvimento e instrução. 


\section{BibliDS Analysis of job offers for reference librarians}

\section{Conclusão}

Este trabalho buscou identificar o perfil dos bibliotecários e bibliotecários de referência exigidos em ofertas de emprego disponíveis nos sites Indeed e Jobs. A pesquisa evidenciou que a maioria dos anúncios em ambos os sites é proveniente de instituições de ensino universitárias, com ofertas para bibliotecários, bibliotecários universitários e bibliotecários de referência.

Embora a habilidade de instruir usuários seja esperada de um bibliotecário de referência, alguns anúncios exigem experiência com instrução. O perfil do profissional requerido também pode render outras discussões, principalmente quanto à ampla gama de funções demandadas ao bibliotecário, desde serviços como referência, processamento técnico, desenvolvimento de coleções, até a produção de material instrucional e conhecimento especializado em fontes jurídicas.

A maioria dos anúncios demanda o bacharelado como requisito básico, pós-graduação em Biblioteconomia e Ciência da informação ou equivalente. O perfil do profissional requerido pela maioria dos anúncios é o de um profissional com habilidades de comunicação oral e escrita, experiência em gestão e organização e comprometimento com o seu trabalho e com a instituição empregadora. 


\section{Referências}

BARDIN, L. (2010) Análise de conteúdo. Ed. Lisboa: Edições 70.

CAMPELLO, B.; ABREU, V.L.F. (2005). Competência informacional e formação do bibliotecário. Perspectivas em Ciência da Informação, 10(2), 178-193. Recuperado de: <portaldeperiodicos.eci.ufmg.br/index.php/pci/article/view/2/150>.

CARVALHO, L. S., LUCAS, E. O. (2005) Serviço de referência e informação: do tradicional ao on-line. In: Encontro Nacional de Ciência da Informação, Salvador, BA. Anais... Recuperado de:

<http://www.cinform.ufba.br/vi anais/docs/LidianeElaineServicoReferencia.pdf>.

CHIAVENATO, I. (2000) Introdução à Teoria Geral da Administração. Rio de Janeiro: Campus.

GIL, A. C. (2002). Como elaborar projetos de pesquisa. São Paulo: Atlas.

GROGAN, D. (2001) A prática do serviço de referência. Brasília: Briquet de Lemos.

LOPES, M. I. SILVA, E. L. (2011) A internet, a mediação e a desintermediação da informação. DataGramaZero, 12(2). Recuperado de: <http://www.dgz.org.br/abr11/F | art.htm>.

MERLO VEGA, J. A. (2000) El servicio bibliotecario de referencia. Anales de Documentación, Murcia, n. 3, p. 96-126. Recuperado de: <http://revistas.um.es/analesdoc/article/view/2471>.

26(11) Recion) Pregunte a un bibliotecario: servicios de referencia em línea. Revista Española de Documentación Científica, 26(11), Recuperado de: <http://exlibris.usal.es/merlo/escritos/pregunte.htm>.

PACHECO, R. C. S. KERN, V. M. Transparência e gestão do conhecimento por meio de um banco de teses e dissertações: a experiência do PPGEP/UFSC. Ciência da Informação, Brasília, 30(3), p. 64-72. Recuperado de: <http://revista.ibict.br/index.php/ciinf/article/viewArticle/199>.

SAYÃO, L. F. (2009) Afinal, o que é biblioteca digital? Revista USP, n. 80. Recuperado de: $<$ http://www.revistasusp.sibi.usp.br/scielo.php?script= sci arttext\&pid=S0103-99892009000100002\&lng=pt\&nrm=iso>.

SILVA, C.C.M. (2006) O Perfil do Bibliotecário de Referência das Bibliotecas Universitárias do Estado de Santa Catarina. (Dissertação de Mestrado em Ciência da Informação - UFSC). 


\section{Biblios Analysis of job offers for reference librarians}

\section{Dados das autoras}

Ana Cláudia Zandavalle

Acadêmica de Biblioteconomia da Universidade Federal de Santa Catarina, Florianópolis, Brasil

aninhazandaufsc@gmail.com

Daniela Capri

Acadêmica de Biblioteconomia da Universidade Federal de Santa Catarina, Florianópolis, Brasil

dccapri@gmail.com

Renata Duarte de Borja

Acadêmica de Biblioteconomia da Universidade Federal de Santa Catarina, Florianópolis, Brasil

renatardb@gmail.com

Miriam Vieira da Cunha

Professora do Departamento de Ciência da Informação da Universidade Federal de Santa Catarina, Florianópolis, Brasil

mcunha@cin.ufsc.br

Recebido - Received: 2011-07-15

Aceito - Accepted: 2011-09-30

\section{(cc) EY-NC-ND}

This work is licensed under a Creative Commons Attribution-Noncommercial-No Derivative Works 3.0 United States License.

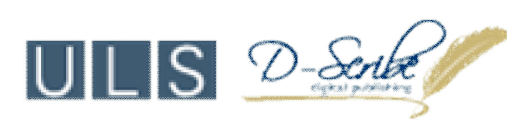

This journal is published by the University Library System of the University of Pittsburgh as part of its $\underline{D-S c r i b e}$ Digital Publishing Program and is cosponsored by the University of Pittsburgh Press. 